\title{
Adult Favorable Prognosis Hodgkin Lymphoma
}

National Cancer Institute

\section{Source}

National Cancer Institute. Adult Favorable Prognosis Hodgkin Lymphoma. NCI

Thesaurus. Code C114807.

A Hodgkin lymphoma with favorable prognosis that occurs during adulthood. 